\title{
Schiff base transition metal complexes for Suzuki-Miyaura cross-coupling reaction
}

\author{
RASHEEDA M ANSARI and BADEKAI RAMACHANDRA BHAT* \\ Catalysis and Material Chemistry Laboratory, Department of Chemistry, National Institute of Technology \\ Karnataka, Mangalore, Karnataka 575 025, India \\ E-mail: ram@nitk.edu.in
}

MS received 11 April 2017; revised 12 July 2017; accepted 13 July 2017; published online 19 August 2017

\begin{abstract}
Schiff base ligand and its complex with iron (Fe), cobalt $(\mathrm{Co})$, nickel $(\mathrm{Ni})$ and copper $(\mathrm{Cu})$ ions were synthesized using 4-aminoacetophenone and salicylaldehyde and characterized. FTIR spectrum shows that bidentate coordination of metal ions with ligand where $\mathrm{O}, \mathrm{N}$ are electron donating sites of azomethine group. The geometry of the complexes was deduced from the calculated magnetic moment values and SCXRD analysis. All complexes were studied for their catalytic activity in Suzuki-Miyaura cross-coupling reaction with $\mathbf{C u}-\mathbf{L}$ complex showing excellent coupling yield among others. The catalytic activity data show promising results in coupling efficiency, employing cheap, abundant and green metals.
\end{abstract}

Keywords. Suzuki-Miyaura cross-coupling; transition metal complex; schiff base; biphenyl.

\section{Introduction}

Schiff base is a unique class of ligands with different donor atoms exhibiting fascinating coordination style towards numerous metal ions. ${ }^{1,2}$ The compatibility for the chelation of the Schiff bases towards the transition metal ions is applied in preparing their metal complexes. Schiff base metal complexes are well-known for their easy synthesis, stability and wide application. ${ }^{3,4}$ Metal complexes containing Schiff base ligand have been studied for their interesting and important properties such as their ability to bind with oxygen, photochromism, antibacterial and antifungal properties, catalytic activity in olefins, hydrogenation and complexing proficieency towards a few toxic metals. ${ }^{5,6}$

Transition metal-catalyzed cross-coupling reactions are undoubtedly the most utilized means for forming $\mathrm{C}-\mathrm{C},{ }^{7} \mathrm{C}-\mathrm{N},{ }^{8} \mathrm{C}-\mathrm{O},{ }^{9}$ and $\mathrm{C}-\mathrm{S}{ }^{10}$ bonds in synthetic organic chemistry. Researchers are trying to develop simple, fast, cheap and more efficient methodologies for different coupling reactions. ${ }^{11}$ The Suzuki crosscoupling reaction or simply Suzuki reaction is one of the most used cross-coupling reactions in modern organic synthesis, wherein a biphenyl molecule is being synthe-

\footnotetext{
*For correspondence
}

sized through coupling of an aryl halide or triflate to phenylboronic acid in the presence of a catalyst. ${ }^{12}$ In practice, palladium $(\mathrm{Pd})$ complexes are common catalysts for Suzuki coupling reactions,${ }^{13-16}$ however, they being expensive and less abundant it is required to search for more cost-effective and eco-friendly catalysts.

Coupling of various vinyl halides with a Grignard reagent in the presence of iron catalysts has been reported. ${ }^{17}$ Cross coupling of aromatic iodides with terminal acetylenes using iron salts and $\mathrm{CuI}$ have been done. ${ }^{18} \mathrm{~A}$ series of $\mathrm{Fe}(\mathrm{III})$ complexes supported by chloro- and fluoro-functionalized amine-bis(phenolate) ligands has been used for $\mathrm{C}-\mathrm{C}$ coupling of aryl and allyl Grignard reagents with alkyl halides. ${ }^{19}$ Coupling of aryl halides with 2-Chloropyrazine having a wide variety of functional groups has been reported with cobalt catalyst. ${ }^{20}$ Moreover, cobalt-catalyzed electrochemical cross-coupling of functionalized phenyl halides with 4chloroquinoline derivatives have also been surveyed. ${ }^{21}$ However, cobalt catalyzed $\mathrm{C}-\mathrm{C}$ coupling has been investigated which is applicable in the synthesis of important pharmaceutical intermediates. ${ }^{22}$ Additionally, nickel salt was used for direct reductive cross coupling of aryl halides with phenylboronic acid. ${ }^{23}$ Also, copper catalysts for cross-couplings of different organometallic

Electronic supplementary material: The online version of this article (doi:10.1007/s12039-017-1347-6) contains supplementary material, which is available to authorized users. 
reagents with alkyl, aryl and heteroaryl halides have been studied. ${ }^{24}$

There are various examples of activity of Schiff base complexes in homogeneous as well as heterogeneous catalysis. ${ }^{25,26} \mathrm{~N}, \mathrm{O}$ donor atom Schiff base complexes were intensively studied for catalytic and biological properties. ${ }^{27}$ Transition metal complexes (apart from Pd) with Schiff base have been widely used in applications such as in polymer industry, dye industry, medicinal chemistry, agrochemical and biological activities. ${ }^{28}$ Promising catalytic activity shown by these transition metal complexes have encouraged the researchers to develop cheaper catalysts for coupling reactions compared to the ones with Pd. Exploratory studies on employing the first-row transition metal complexes as precatalysts in coupling activity is an ongoing research topic because of the several benefits like low cost and abundance of metal, ease of synthesis, facile scale-up, etc. ${ }^{29}$ Contributing to this subject of research, we have attempted in this work to synthesize a few Schiff base complexes of $\mathrm{Fe}, \mathrm{Co}, \mathrm{Ni}$ and $\mathrm{Cu}$ ions. The scope of our research study is to throw more light on the chelation behavior of Schiff base ligand towards the chosen metal ions and their catalytic activity in the coupling of various substituted aryl halides with phenylboronic acid.

\section{Experimental}

\subsection{Materials and reagents}

All chemicals were of analytical reagent (AR) grade and used without any further purification. 4-aminoacetophenone, salicylaldehyde, nickel acetate tetrahydrate, copper acetate monohydrate, cobalt acetate tetrahydrate and ferric chloride hexahydrate, potassium carbonate, sodium carbonate were purchased from Merck India and used as received. Acetonitrile, 1,4-dioxane, toluene, ethyl alcohol, diethyl ether, dichloromethane (DCM), potassium tertiary butoxide, cesium carbonate and triethylamine used in the study were purchased from Sigma-Aldrich.

\subsection{Instrumentation}

The $\mathrm{C}, \mathrm{H}$ and $\mathrm{N}$ contents of the ligand and metal complexes were determined using microanalysis Thermoflash EA1112 series elemental analyzer. FTIR results were obtained on a Bruker-Alpha ECO-ATR FTIR spectrophotometer. The spectra were obtained as $\mathrm{KBr}$ pellets. Electronic spectra of ligand and complexes were measured on Analytik Jena SPECORD S600 UV-Vis spectrophotometer in the $200-800 \mathrm{~nm}$ range. The magnetic susceptibilities of the complexes were recorded at room temperature on a Sherwood UK magnetic balance, $\mathrm{Hg}\left[\mathrm{Co}(\mathrm{SCN})_{4}\right]$ was used as a calibrant. Molecular mass was determined using a Waters Q-ToF micro mass spectrometer with an ESI source. The ${ }^{1} \mathrm{H}$ NMR spectrum of the ligand was recorded in Bruker AV 400 instrument using TMS as an internal standard. Thermogravimetric measurements were performed on (EXSTAR-6000) using nitrogen as the carrier gas (flow rate: $50 \mathrm{~mL} / \mathrm{min}$ ). The heating rate was $10^{\circ} \mathrm{C} / \mathrm{min}$. The coupling reaction product analysis was carried out using Gas Chromatography (GC) (Shimadzu 2014, Japan), siloxane Restek capillary column (30 m length and $0.25 \mathrm{~mm}$ diameter) and Flame Ionization Detector (FID). The initial column temperature was increased from 60 to $150^{\circ} \mathrm{C}$ at the rate of $10^{\circ} \mathrm{C} / \mathrm{min}$ and then to $220^{\circ} \mathrm{C}$ at the rate of $40^{\circ} \mathrm{C} / \mathrm{min}$. Nitrogen gas was used as the carrier gas.

\subsection{Synthesis of Schiff base ligand $(\mathbf{L})$}

4-aminoacetophenone $(0.135 \mathrm{~g}, 1 \mathrm{mmol})$ and salicylaldehyde $(0.122 \mathrm{~g}, 1 \mathrm{mmol})$ were dissolved in ethanol and heated to $60^{\circ} \mathrm{C}$ in a $50 \mathrm{~mL}$ round bottom flask. The reaction mixture was then refluxed for $3 \mathrm{~h}$ followed by filtration of obtained product, washing with diethyl ether, re-crystallization using ethanol and drying. Yield: $80.40 \%$; Color: Yellow; $\mathrm{C}_{15} \mathrm{H}_{13} \mathrm{NO}_{2}$ : Anal. Found: C, 75.94; H, 5.40; N, 5.05\% Calc.: C, 75.90; H, 5.48; N, 5.85\%. Mol. Wt.: 239.00: FTIR (KBr) $\left(\nu / \mathrm{cm}^{-1}\right): 3333$ $(\mathrm{O}-\mathrm{H}), 1411-1490(\nu \mathrm{C}=\mathrm{C}$ aromatic $), 1577(\nu \mathrm{C}=\mathrm{N}), 1279$ ( $\nu \mathrm{C}-\mathrm{O}), 1112-1166(\nu \mathrm{C}-\mathrm{N}), 3046.22(\nu \mathrm{C}-\mathrm{H}) ;{ }^{1} \mathrm{H}$ NMR $(\delta$, ppm in $\left.\mathrm{CDCl}_{3}\right): 12.87(\mathrm{~s}, 1 \mathrm{H}) ; 8.63(\mathrm{~s}, 1 \mathrm{H}) ; 8.04(\mathrm{~d}, 2 \mathrm{H}) ; 8.02$ (d, 2H); 7.46-6.94 (m, 4H); 2.60 (s, 3H) (Scheme 1).

\subsection{Synthesis of metal complexes}

2.4a Synthesis of complex $\mathbf{C}-\mathbf{1}$ : The metal complex $\mathbf{C}$ 1 was prepared by the addition of a hot solution of the ferric chloride $(0.270 \mathrm{~g}, 1 \mathrm{mmol})$ in $50 \% \mathrm{v} / \mathrm{v}$ mixture of ethanol in water $(5 \mathrm{~mL})$ to the hot solution of the synthesized Schiff base $(0.239 \mathrm{~g}, 2 \mathrm{mmol})$ in the same solvent system $(5 \mathrm{~mL})$. The mixture was refluxed with continuous stirring for $5 \mathrm{~h}$. The reaction mixture was filtered, washed with methanol and dried. Yield: 84.50\%; Color: Dark purple; $\mathrm{C}_{30} \mathrm{H}_{24} \mathrm{ClFeN}_{2} \mathrm{O}_{4}$ : Anal. Found: C, 59.92; H, 4.35; N, 4.45\% Calc.: C, 59.83; H, 4.33; N, 4.63\%. Mol. Wt.: 568.10: FTIR $(\mathrm{KBr})\left(\nu / \mathrm{cm}^{-1}\right): 3351.84$

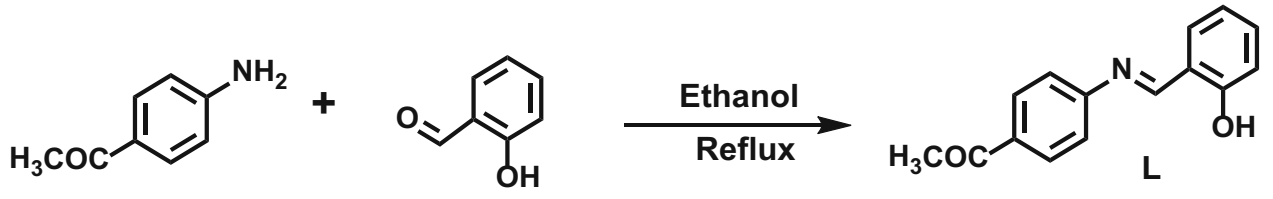

Scheme 1. Synthesis of Schiff base ligand (L). 
<smiles>CC(=O)c1ccc(/N=C/c2ccccc2O)cc1</smiles>
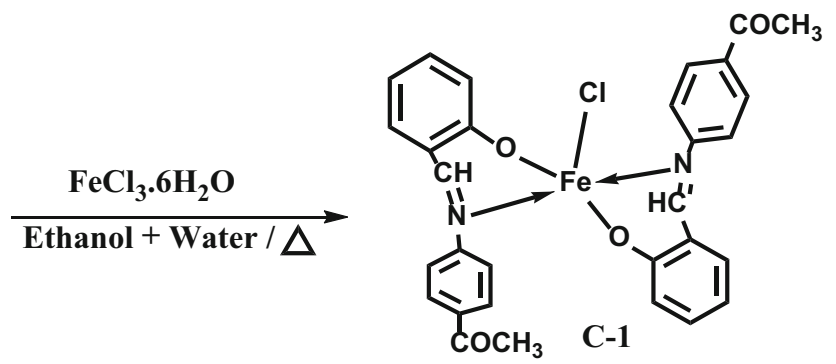

Scheme 2. Synthesis of complex C-1.<smiles>CC(=O)c1ccc(/N=C/c2ccccc2O)cc1</smiles>
$\underset{\text { Ethanol }+ \text { Water } / \triangle}{\stackrel{\mathrm{Co}\left(\mathrm{OCOCH}_{3}\right)_{2} \cdot 4 \mathrm{H}_{2} \mathrm{O}}{\longrightarrow}}$

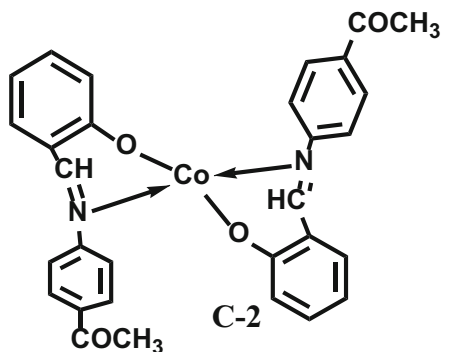

Scheme 3. Synthesis of complex C-2.<smiles>CC(=O)c1ccc(/N=C/c2ccccc2O)cc1</smiles>
$\underset{\text { Ethanol }+ \text { Water } / \triangle}{\stackrel{\mathrm{Ni}\left(\mathrm{OCOCH}_{3}\right)_{2} \cdot 4 \mathrm{H}_{2} \mathrm{O}}{\longrightarrow}}$<smiles>CC(=O)c1ccc(N2COc3ccccc3N(c3ccc(C(C)=O)cc3)C2)cc1</smiles>

Scheme 4. Synthesis of complex C-3.

$(\mathrm{O}-\mathrm{H}), 1425-1475(\nu \mathrm{C}=\mathrm{C}$ aromatic $), 1596(\nu \mathrm{C}=\mathrm{N}), 1279$ $(\nu \mathrm{C}-\mathrm{O}), 1112-1166(\nu \mathrm{C}-\mathrm{N}), 3061.86(\nu \mathrm{C}-\mathrm{H})($ Scheme 2).

2.4b Synthesis of complex C-2: The metal complex C-2 was prepared by the addition of a hot solution of the cobalt acetate tetrahydrate $(0.249 \mathrm{~g}, 1 \mathrm{mmol})$ in $50 \% \mathrm{v} / \mathrm{v}$ mixture of ethanol in water $(5 \mathrm{~mL})$ to the hot solution of the synthesized Schiff base $(0.239 \mathrm{~g}, 2 \mathrm{mmol})$ in the same solvent system $(5 \mathrm{~mL})$. The mixture was refluxed with continuous stirring for $5 \mathrm{~h}$. The reaction mixture was filtered, washed with methanol and dried. Yield: 68.60\%; Color: Orange; $\mathrm{C}_{30} \mathrm{H}_{24} \mathrm{CoN}_{2} \mathrm{O}_{4}$ : Anal. Found: $\mathrm{C}, 64.31 ; \mathrm{H}, 4.75$; N, 4.56\% Calc.: C, 64.43; H, 4.90; N, 4.70\%. Mol. Wt.: 535.90: FTIR $(\mathrm{KBr})\left(\mathrm{v} / \mathrm{cm}^{-1}\right): 3421.85(\mathrm{O}-\mathrm{H}), 1356-1437$ $(\nu \mathrm{C}=\mathrm{C}$ aromatic $), 1556.55(\nu \mathrm{C}=\mathrm{N}), 1264(\nu \mathrm{C}-\mathrm{O}), 3063(\nu \mathrm{C}-$ H) (Scheme 3).

2.4c Synthesis of complex C-3: Nickel complex C-3 was prepared by the addition of a hot solution of the nickel acetate tetrahydrate $(0.248 \mathrm{~g}, 1 \mathrm{mmol})$ in $50 \% \mathrm{v} / \mathrm{v}$ mixture of ethanol in water $(5 \mathrm{~mL})$ to the hot solution of the synthesized Schiff base $(0.239 \mathrm{~g}, 2 \mathrm{mmol})$ in the same solvent system $(5 \mathrm{~mL})$. The mixture was refluxed with continuous stirring for $5 \mathrm{~h}$. The reaction mixture was filtered, washed with diethyl ether and dried. Yield: 78.0; Color: Bright green; $\mathrm{C}_{30} \mathrm{H}_{24} \mathrm{~N}_{2} \mathrm{NiO}_{4}$ : Anal. Found: C, 67.00; H, 4.81; N, 5.11\% Calc.: C, 67.07; H, 4.88; N, 5.21\%. Mol. Wt.: 535.85: FTIR $(\mathrm{KBr})\left(\mathrm{v} / \mathrm{cm}^{-1}\right): 3366(\mathrm{O}-\mathrm{H}), 1419-1445(\mathrm{\nu C}=\mathrm{C}$ aromatic $)$, $1588(\nu \mathrm{C}=\mathrm{N}), 1279(\nu \mathrm{C}-\mathrm{O}), 1124-1178(\nu \mathrm{C}-\mathrm{N}), 3056.73$ $(\nu \mathrm{C}-\mathrm{H})$ (Scheme 4).

2.4d Synthesis of complex C-4: Copper complex C-4 was prepared by the addition of a hot solution of the copper acetate monohydrate $(0.199 \mathrm{~g}, 1 \mathrm{mmol})$ in $50 \% \mathrm{v} / \mathrm{v}$ mixture of ethanol in DCM $(5 \mathrm{~mL})$ to the hot solution of the synthesized Schiff base $(0.239 \mathrm{~g}, 2 \mathrm{mmol})$ in ethanol $(5 \mathrm{~mL})$. The mixture was refluxed with continuous stirring for $5 \mathrm{~h}$. Formed product was filtered and washed with 50\% ethanol-water mixture, diethyl ether and dried. Yield: 80.50\%; Color: Brown; $\mathrm{C}_{30} \mathrm{H}_{24} \mathrm{CuN}_{2} \mathrm{O}_{4}$ : Anal. Found: C, 66.68; H, 4.40; N, 5.17\% Calc.: C, 66.72; H, 4.48; N, 5.19\%. Mol. Wt.: 539.00: FTIR $(\mathrm{KBr})\left(\mathrm{v} / \mathrm{cm}^{-1}\right): 3446(\mathrm{O}-\mathrm{H}), 1442-1531(\nu \mathrm{C}=\mathrm{C}$ aromatic $)$, $1606(\nu \mathrm{C}=\mathrm{N}), 1270(\nu \mathrm{C}-\mathrm{O}), 1150-1181(\nu \mathrm{C}-\mathrm{N}), 2993.81$ $(\nu \mathrm{C}-\mathrm{H})($ Scheme 5). 
<smiles>CC(=O)c1ccc(/N=C/c2ccccc2O)cc1</smiles>

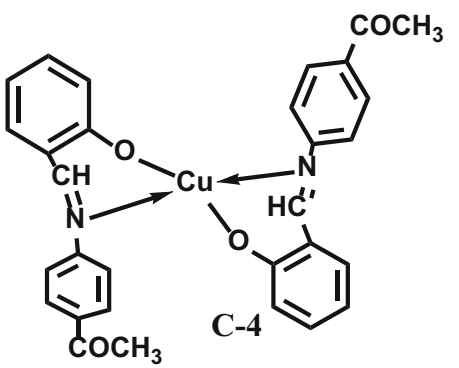

Scheme 5. Synthesis of complex C-4.

\section{$2.5 X$-ray crystallography}

Ligand and complex (C-4) crystal were obtained by a slow evaporation method using 50\% DCM in ethanol as solvent. The X-ray diffraction studies for these crystals were performed on a Bruker APEX-II CCD diffractometer with Mo $\mathrm{K} \alpha$ radiation $\left(\lambda_{0}=0.71073 \AA\right)$ at $296 \mathrm{~K}$. The structure was solved using SHELXL-2007/2014 software and refined by full matrix least square methods.

\subsection{General procedures for the Suzuki reaction}

Aryl halide $(1.0 \mathrm{mmol})$ was added to a mixture of phenylboronic acid $(1.5 \mathrm{mmol})$, Schiff base complex $(0.02 \mathrm{mmol})$ and base $(3.0 \mathrm{mmol})$ in $3 \mathrm{~mL}$ of solvent and heated to $80^{\circ} \mathrm{C}$ for $16 \mathrm{~h}$. The mixture was then cooled to room temperature. After cooling, the organic phase was analyzed by gas chromatography. Internal standard was used and calibrated against each and every one of the cross-coupling products. Biphenyl was obtained as a side product due to the homocoupling of phenylboronic acid.

\section{Results and Discussion}

\section{$3.1{ }^{1} H$ NMR and mass spectra}

The ${ }^{1} \mathrm{H}$ NMR (400 MHz) spectrum of ligand (L) was recorded in $\mathrm{CDCl}_{3}$ (Figure S1 in Supplementary Information). The electron impact mass spectra of the Schiff base and metal complexes were recorded and investigated at $50 \mathrm{eV}$ of electron energy. The important mass fragmentations of the ligand and complexes are shown in the spectra (Figures S2-S6 in Supplementary Information).

\subsection{FTIR spectra}

The synthesized ligand and complex molecules were examined by the FTIR analysis (Figures S7-S11 in Supplementary Information). The new bands in the range $580-672 \mathrm{~cm}^{-1}$ in complexes, tentatively assign coordination of metal with oxygen atom $v(\mathrm{M}-\mathrm{O}) .{ }^{30}$ The bands

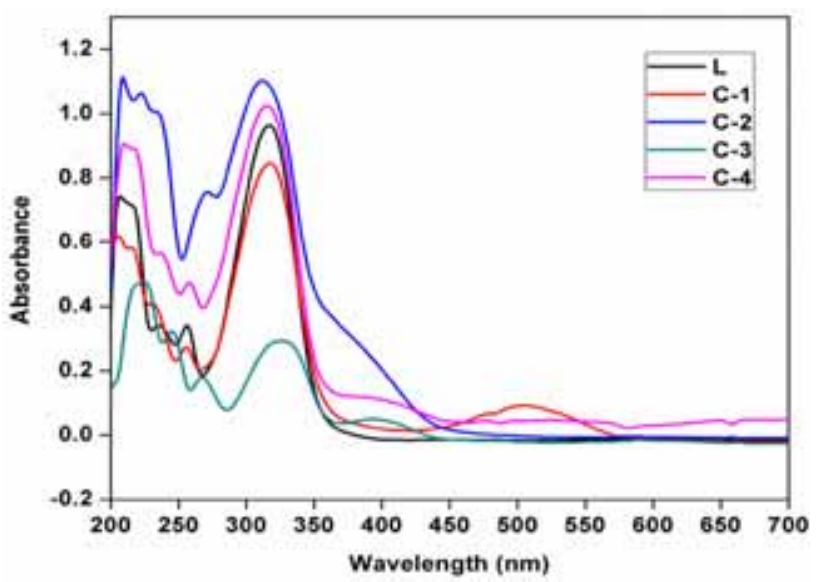

Figure 1. UV-Vis spectra of ligand and complexes in ethanol (Concentration $=10^{-3} \mathrm{M}$, Path length $=1 \mathrm{~cm}$ ).

which appear around $400-500 \mathrm{~cm}^{-1}$ in the spectra of the complexes may be assigned to the coordination of metal with a nitrogen atom.

\subsection{Electronic absorption spectra}

The electronic spectra of synthesized ligand and complexes were recorded in ethanol solvent $\left(10^{-3} \mathrm{M}\right)$ (Figure 1). Quartz cells with a $1 \mathrm{~cm}$ pathlength were employed in the 200-700 $\mathrm{nm}$ spectral range. The peak in the region $218 \mathrm{~nm}$ is assigned to the $\pi-\pi *$ transitions of aromatic rings. The peak at $310-350 \mathrm{~nm}$ involves $n-\pi^{*}$ transition of the $\mathrm{CH}=\mathrm{N}$ group. ${ }^{31}$ Iron complex shows bands at $210,322,511 \mathrm{~nm}(449-563 \mathrm{~nm})$. In cobalt complex, peaks at 208, 263, 296, $354 \mathrm{~nm}(460-514 \mathrm{~nm})$ were observed. Similarly, nickel complex shows two peaks at 215 and $321 \mathrm{~nm}$ which are due to $\pi-\pi^{*}, \mathrm{n}-\pi^{*}$ transitions, respectively. The electronic spectrum of $\mathrm{Cu}$ complex shows peaks at 213 and $315 \mathrm{~nm}, 402,512 \mathrm{~nm}$ due to $\pi-\pi^{*}$ and $n-\pi *$ respectively.

\subsection{Magnetic susceptibility measurements}

The magnetic moment for iron complex $\mathbf{C}-\mathbf{1}$ was found to be $1.80 \mathrm{BM}$, which indicates that the complex is paramagnetic with one unpaired electron present (Table 1). 
Table 1. Magnetic moment of the complexes.

\begin{tabular}{lc}
\hline Compound & $\mu$ eff. $(\mathrm{BM})$ \\
\hline $\mathbf{C - 1}$ & 1.80 \\
$\mathbf{C}-2$ & 1.73 \\
$\mathbf{C}-3$ & 0.33 \\
$\mathbf{C - 4}$ & 1.65 \\
\hline
\end{tabular}

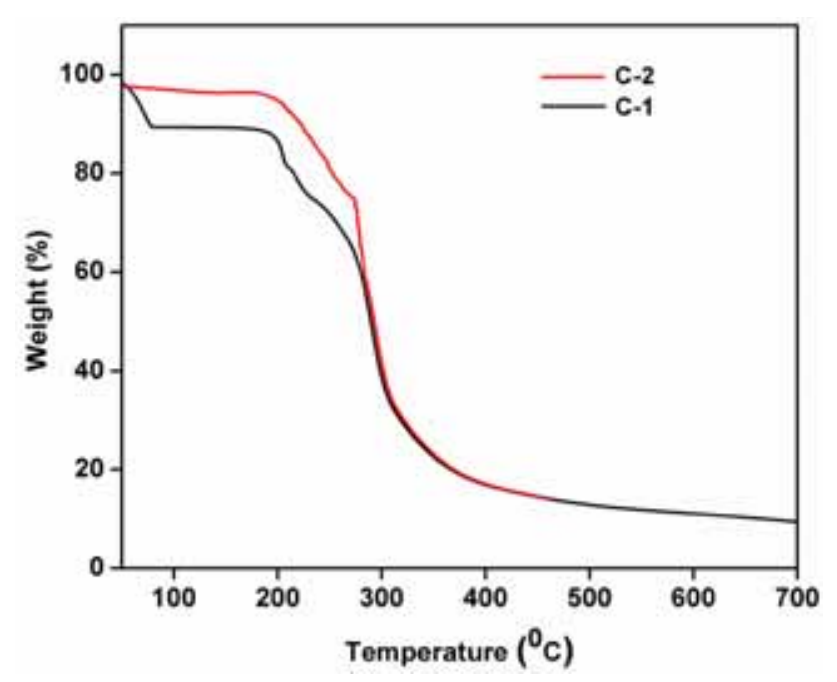

Figure 2. TGA curve of complex C-1 and C-2.

The observed magnetic moment supports the iron complex to be in low-spin Fe (III) state. Similarly, cobalt complex C-2 shows the magnetic moment of 1.73 BM with one unpaired electron which indicates that cobalt complex possesses low spin Co (II) state. The almost zero magnetic moment of nickel complex $\mathbf{C - 3}$ clearly confirms the absence of any unpaired electrons. It also affirms the diamagnetic nature of the complex with a possible square planar geometry. ${ }^{32}$ The magnetic moment of 1.65 BM supports the copper complex $\mathbf{C}-4$ to be in high spin $\mathrm{Cu}$ (II) state with tetrahedral geometry.

\subsection{Thermogravimetric analysis}

The thermal degradations of synthesized complex (C-1 and $\mathbf{C - 2}$ ) were studied using temperature range from 50 to $700^{\circ} \mathrm{C}$. The data from the thermogravimetric analysis clearly indicates the decomposition of the ligand in the temperature range of $180-450^{\circ} \mathrm{C}$. Removal of the ligand molecule proceeds in a single step; further complete decomposition was observed at $\geq 500^{\circ} \mathrm{C}$ (Figure 2).

\subsection{Structure of $\mathbf{L}$ and complex $\mathbf{C}-\mathbf{4}$}

Selected bond lengths and bond angles are listed in Table S1 (Supplementary information). The molecular structures of $\mathbf{L}$ and $\mathbf{C}-\mathbf{4}$ are shown in (Figure 3(a) and (b)).

\subsection{Catalytic activity studies of synthesized complexes for Suzuki reaction}

3.7a Effect of solvent: The catalytic efficiency of the synthesized complexes $\mathbf{C}-\mathbf{1}$ to $\mathbf{C}-\mathbf{4}$ was studied in Suzuki reaction for cross-coupling of 4-bromobenzonitrile and phenylboronic acid (Base: $\mathrm{K}_{2} \mathrm{CO}_{3}$, Concentration of catalyst: $0.02 \mathrm{mmol}$ ) in various solvent media (Figure 4). Among the different solvents used, highest catalytic activity was observed with acetonitrile. Moderate catalyst activities were found in other solvents such as ethanol, THF, 1,4-dioxane and toluene. Acetonitrile was chosen as the optimum solvent for carrying out the reactions. The reaction is found to work out best at its reflux temperature.

3.7b Effect of base: Further, the effect of a base on the reaction performance was studied using different bases such as $\mathrm{K}_{2} \mathrm{CO}_{3}, \mathrm{Na}_{2} \mathrm{CO}_{3}, \mathrm{Et}_{3} \mathrm{~N}, \mathrm{Cs}_{2} \mathrm{CO}_{3}$ and $\mathrm{KO}^{\mathrm{t}} \mathrm{Bu}$ in acetonitrile solvent (Figure 5). As shown in Figure 5, $\mathrm{Et}_{3} \mathrm{~N}$ is the desirable base for the reaction with high
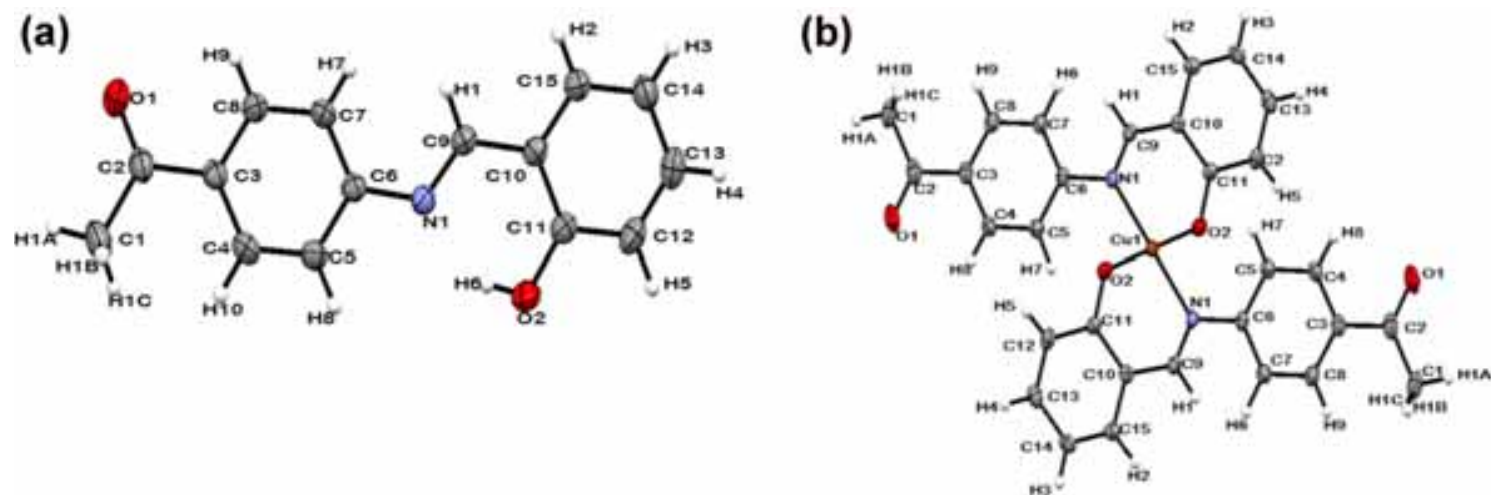

Figure 3. Single crystal structure of (a) ligand (L) and (b) copper Schiff base complex C-4 (displacement ellipsoids are drawn at the $30 \%$ probability level). 


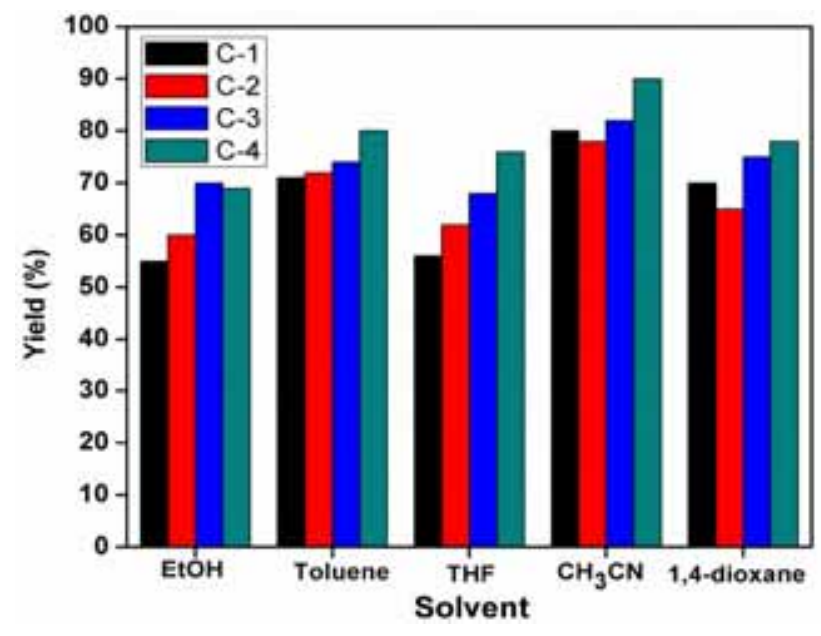

Figure 4. Effect of solvent on Suzuki coupling.

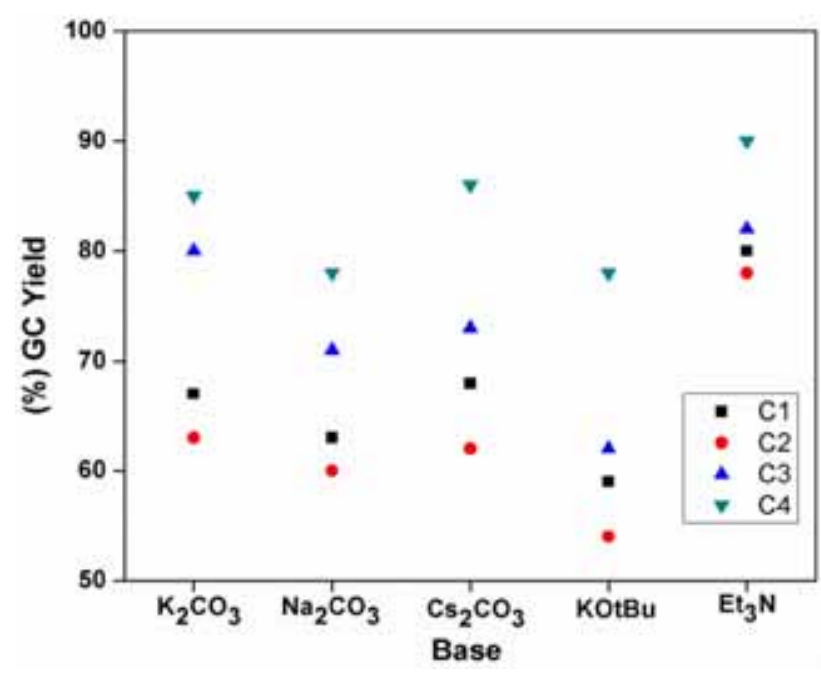

Figure 5. Effect of base on Suzuki coupling.

product yield. In the absence of catalyst, coupling product was formed with very less yield using triethylamine base $(15.5 \%)$ (Scheme 6).

\section{7c Effect of catalyst concentration on the reaction:}

Since catalyst loading in a reaction significantly decides the catalytic efficiency, the amount of catalyst required for effective conversion was another parameter selected and studied. Figure 6 shows the effect of catalyst loading on the yield of reaction. The yield was found to increase with the increase in the amount of catalyst used. However, after the catalyst concentration of $0.02 \mathrm{mmol}$, the yield of the reaction showed a negative trend, possibly

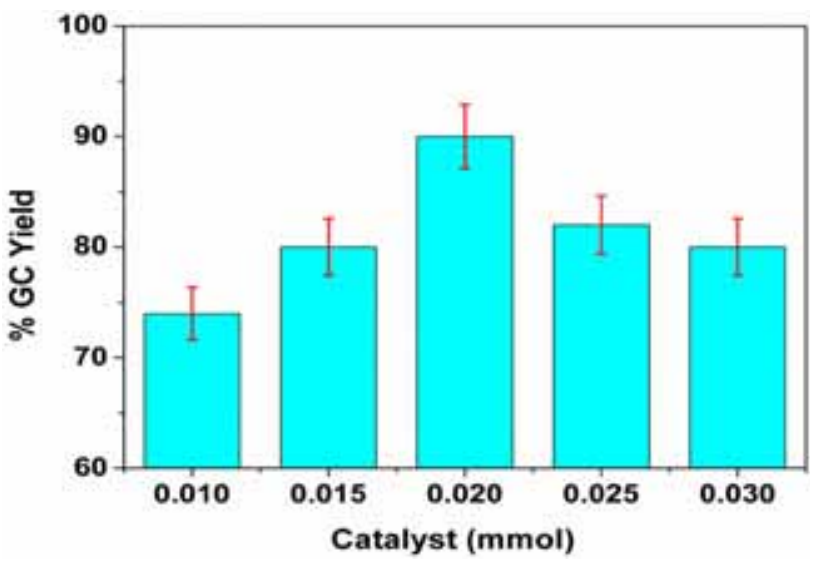

Figure 6. Effect of catalyst concentration.

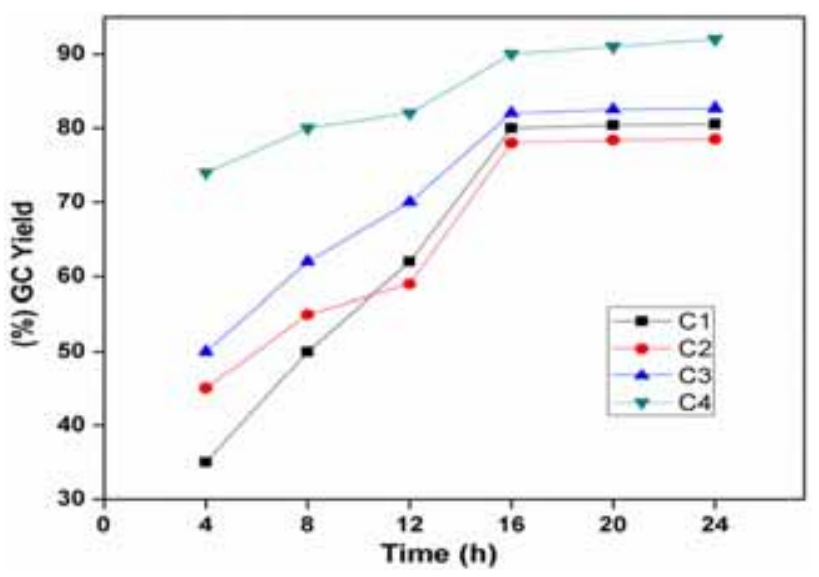

Figure 7. Effect of catalyst concentration.

due to the oxidative addition step of the catalytic cycle getting affected in the presence of increased concentration of catalyst. Thus, we preferred $\mathrm{Et}_{3} \mathrm{~N}$ as the base, acetonitrile as solvent, and $0.02 \mathrm{mmol}$ of the catalyst as the optimal conditions for the reaction.

3.7d Effect of time: Moreover, product yield strictly depends on the reaction time. This was investigated by analyzing the reaction mixture at regular intervals of time. The product conversion was observed to increase with reaction time till the completion at $16 \mathrm{~h}$, beyond which extent of conversion remained almost insignificant (Figure 7). This led us to choose optimal reaction time for coupling as $16 \mathrm{~h}$.

Further, different substituted aryl halides were used to extend the cross-coupling reaction with phenylboronic acid using the optimized reaction conditions. The results

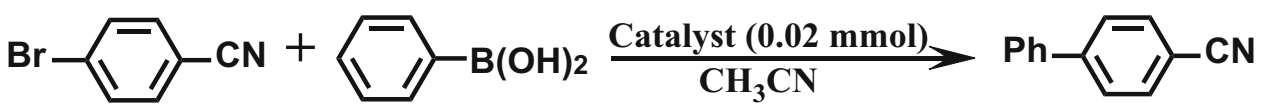

Scheme 6. Suzuki coupling of 4-bromobenzonitrile and phenylboronic acid using synthesized catalyst. 
Table 2. Catalytic studies of synthesized complex for Suzuki-Miyaura cross-coupling reactions of aryl halides with phenylboronic acid.

\begin{tabular}{|c|c|c|c|c|c|c|}
\hline \multirow[t]{2}{*}{ Entry } & \multirow[t]{2}{*}{$\mathrm{R}$} & \multirow[t]{2}{*}{$X$} & \multicolumn{4}{|l|}{ Yield $^{\mathrm{a}, \mathrm{b}}$} \\
\hline & & & $\mathrm{C}-1$ & $\mathrm{C}-2$ & $\mathrm{C}-3$ & C-4 \\
\hline 1 & $\mathrm{OCH}_{3}$ & $\mathrm{Br}$ & 64 & 60 & 64 & 65 \\
\hline 2 & $\mathrm{H}$ & & 55 & 50 & 52 & 62 \\
\hline 3 & $\mathrm{CN}$ & & 82 & 78 & 80 & 90 \\
\hline 4 & $\mathrm{COCH}_{3}$ & & 86 & 83 & 82 & 80 \\
\hline 5 & $\mathrm{NHCOCH}_{3}$ & & 75 & 74 & 73 & 72 \\
\hline 6 & $\mathrm{OH}$ & & 59 & 50 & 55 & 65 \\
\hline 7 & $\mathrm{CH}_{3}$ & & 61 & 54 & 60 & 62 \\
\hline 8 & $\mathrm{~F}$ & & 46 & 40 & 42 & 50 \\
\hline 9 & $\mathrm{OH}$ & I & 72 & 58 & 65 & 75 \\
\hline 10 & $\mathrm{CN}$ & I & 86 & 79 & 81 & 91 \\
\hline
\end{tabular}

${ }^{a}$ Reaction conditions: Aryl halide ( $\left.1 \mathrm{mmol}\right)$, phenylboronic acid $(1.5 \mathrm{mmol}), \mathrm{Et}_{3} \mathrm{~N}(3.0 \mathrm{mmol})$, catalyst $(0.02 \mathrm{mmol})$, solvent $(3 \mathrm{~mL}), 16 \mathrm{~h}$.

${ }^{\mathrm{b}} \mathrm{GC}$ Yield.

for different substituents are summarized in Table 2. An internal standard was used and calibrated against each and every one of the cross-coupling products. Biphenyls were obtained as a side product due to the homocoupling of phenylboronic acid.

\section{Conclusions}

In conclusion, an efficient, cheap, simple, convenient and environmentally benign Schiff base transition metal (Fe, $\mathrm{Co}, \mathrm{Ni}$ and $\mathrm{Cu}$ ) complex has been synthesized and characterized. Suzuki-Miyaura cross-coupling of various aryl halides and phenylboronic acids was catalyzed using the synthesized complexes. Among all the complexes, copper complex-catalyzed Suzuki reaction showed good yield. The reaction proceeds efficiently under a mild condition and the corresponding biphenyls were obtained in excellent yields. This catalytic system is more attractive because it is very cheap compared with palladium. The absence of reducing agent and phosphine ligand in the catalytic system together are other advantages of this system.

\section{Supplementary Information (SI)}

Crystallographic data for the structural analyses of ligand $\mathbf{L}$ and complex $\mathbf{C}-\mathbf{4}$ have been deposited with the Cambridge Crystallographic Data Centre bearing the CCDC Nos. 1486470 and 1486469, respectively. All additional information pertaining to characterization of the compounds using crystallographic data (Table S1), ${ }^{1} \mathrm{H}$ NMR spectra (Figure S1), ESI Mass spectra (Figures
S2 to S6) and FTIR spectra (Figures S7-S11) are given in the supporting information available at www.ias.ac. in/chemsci.

\section{Acknowledgements}

The authors convey their genuine thanks to the National Institute of Technology, Surathkal (Karnataka) for characterization facilities and financial support.

\section{References}

1. Gupta K C and Sutar A K 2008 Catalytic activities of Schiff base transition metal complexes Coord. Chem. Rev. 2521420

2. Dhanaraj C J, Johnson J, Joseph $\mathrm{J}$ and Joseyphus R S 2013 Quinoxaline-based Schiff base transition metal complexes: review J. Coord. Chem. 661416

3. Abu-Dief A M and Mohamed I M A 2015 A review on versatile applications of transition metal complexes incorporating Schiff bases Beni-Suef Univ. J. Basic Appl. Sci. 4119

4. Alias M, Kassum H and Shakir C 2014 Synthesis, physical characterization and biological evaluation of Schiff base M(II) complexes J. Assoc. Arab Univ. Basic Appl. Sci. 1528

5. Malik S, Ghosh S and Mitu L 2011 Complexes of some 3d-metals with a Schiff base derived from 5-acetamido1, 3, 4-thiadiazole-2-sulphonamide and their biological activity J. Serb. Chem. Soc. 761387

6. Raman N, Johnson Raja S, Joseph J and Dhaveethu Raja J 2007 Synthesis, spectral characterization and dna cleavage study of heterocyclic schiff base metal complexes $J$. Chil. Chem. Soc. 521138

7. Anitha P, Manikandan R, Vijayan P, Prakash G, Viswanathamurthi P and Butcher R J 2015 Nickel (II) 
complexes containing ONS donor ligands: Synthesis, characterization, crystal structure and catalytic application towards C-C cross-coupling reactions J. Chem. Sci. 127597

8. Wang Q, Su Y, Li L and Huang H 2016 Transition-metal catalysed C-N bond activation Chem. Soc. Rev. 451257

9. Guo P 2015 Gold-catalyzed formation of $\mathrm{C}-\mathrm{O}$ and $\mathrm{C}-\mathrm{C}$ bonds: An efficient domino reaction synthesis of functionalized furans Catal. Commun. 6858

10. Guan P, Cao C, Liu Y, Li Y, He P, Chen Q, Liu G and Shi Y 2012 Efficient nickel/N-heterocyclic carbene catalyzed C-S cross-coupling Tetrahedron Lett. 535987

11. Jin M-J and Lee D-H 2010 A Practical Heterogeneous Catalyst for the Suzuki, Sonogashira, and Stille coupling reactions of unreactive aryl chlorides Angew. Chem. Int. Ed. 491119

12. Das P and Linert W 2016 Schiff base-derived homogeneous and heterogeneous palladium catalysts for the Suzuki-Miyaura reaction Coord. Chem. Rev. 3111

13. Roymahapatra G, Samanta T, Seth S K, Mahapatra A, Chattopadhyay S K and Dinda J 2015 N, N'Olefin functionalized Bis-Imidazolium Pd (II) chloride $\mathrm{N}$-Heterocyclic carbene complex builds a supramolecular framework and shows catalytic efficacy for ' $\mathrm{C}$ C'coupling reactions J. Chem. Sci. 1271057

14. Ghorbani-Vaghei R, Hemmati S and Hekmati M 2016 Pd immobilized on modified magnetic $\mathrm{Fe}_{3} \mathrm{O}_{4}$ nanoparticles: Magnetically recoverable and reusable $\mathrm{Pd}$ nanocatalyst for Suzuki-Miyaura coupling reactions and Ullmanntype N-arylation of indoles J. Chem. Sci. 1281157

15. Balsane K E, Shendage S S and Nagarkar J M 2015 Efficient Sonogashira and Suzuki-Miyaura coupling reaction catalyzed by Pd-nanoparticles J. Chem. Sci. 127 425

16. Siddiqui M M, Waheed M, Bhat S A and Balakrishna M S 2015 Application of quinoxaline based diimidazolium salt in palladium catalyzed cross-coupling reactions $J$. Chem. Sci. 127879

17. Tamura M and Kochi J K 1971 Vinylation of Grignard reagents. Catalysis by iron J. Am. Chem. Soc. 931487

18. Rao Volla C M and Vogel P 2008 Iron/copper-catalyzed C-C cross-coupling of aryl iodides with terminal alkynes Tetrahedron Lett. 495961

19. Reckling A M, Martin D, Dawe L N, Decken A and Kozak C M 2011 Structure and C-C cross-coupling reactivity of iron(III) complexes of halogenated aminebis(phenolate) ligands J. Org. Chem. 696787
20. Bégouin J-M and Gosmini C 2009 Cobalt-catalyzed cross-coupling between in situ prepared arylzinc halides and 2-chloropyrimidine or 2-chloropyrazine J. Org. Chem. 74322

21. Le Gall E, Gosmini C, Nédélec J-Y and Périchon J 2001 Cobalt-catalyzed electrochemical cross-coupling of functionalized phenyl halides with 4-chloroquinoline derivatives Tetrahedron Lett. 42267

22. Cahiez G and Moyeux A 2010 Cobalt-catalyzed crosscoupling reactions Chem. Rev. 1101435

23. Goudarzian N, Gholinejad M and Ghahramani P 2011 Recyclable nickel catalysed Suzuki-Miyaura reaction in the presence of polyethyleneimine under phosphine-free conditions in ethylene glycol\# J. Chem. Sci. 123485

24. Thapa S, Shrestha B, Gurung S K and Giri R 2015 Copper-catalysed cross-coupling: an untapped potential Org. Biomol. Chem. 134816

25. Silva A R, Budarin V, Clark J H, Castro B de and Freire C 2005 Chiral manganese(III) Schiff base complexes anchored onto activated carbon as enantioselective heterogeneous catalysts for alkene epoxidation Carbon $\mathbf{4 3}$ 2096

26. Zhang X, Llabrés i Xamena FX and Corma A 2009 Gold(III)-metal organic framework bridges the gap between homogeneous and heterogeneous gold catalysts J. Catal. 265155

27. Ejidike I P and Ajibade P A 2015 Transition metal complexes of symmetrical and asymmetrical Schiff bases as antibacterial, antifungal, antioxidant, and anticancer agents: progress and prospects Rev. Inorg. Chem. 35191

28. Prakash A and Adhikari D 2011 Application of Schiff bases and their metal complexes-a review Int. J. Chem. Tech. Res. 31891

29. Cozzi P G 2004 Metal-Salen Schiff base complexes in catalysis: practical aspects Chem. Soc. Rev. 33410

30. Kurup M R P, Varghese B, Sithambaresan M, Krishnan S, Sheeja S R and Suresh E 2011 Synthesis, spectral characterization and crystal structure of copper(II) complexes of 2-benzoylpyridine-N(4)-phenylsemicarbazone Polyhedron 3070

31. Raman N, Raja J D and Sakthivel A 2007 Synthesis, spectral characterization of Schiff base transition metal complexes: DNA cleavage and antimicrobial activity studies J. Chem. Sci. 119303

32. Cristóvão B 2011 Spectral, thermal and magnetic properties of $\mathrm{Cu}$ (II) and $\mathrm{Ni}$ (II) complexes with Schiff base ligands J. Serb. Chem. Soc. 761639 